\title{
UPPER AND LOWER BOUNDS OF THE NORM OF SOLUTIONS OF DIFFERENTIAL EQUATIONS
}

\author{
V. LAKSHMIKANTHAM ${ }^{1}$
}

Consider the differential system

$$
z^{\prime}=f(x, z)
$$

under the assumptions:

(i) $x$ is a real variable, $z$ and $f$ are finite dimensional complex vectors with $n$ components $z_{i}$ and $f_{i}$ respectively,

(ii) $f$ is continuous in $(x, z)$ for all $z$ and for all $x$ in $a \leqq x \leqq b$. Define $|z|=\sum_{i=1}^{n}\left|z_{i}\right|$. Then we have the following

THEOREM 1. Let the function $g(x, u) \geqq 0$ be continuous in the region $a \leqq x \leqq b, u \geqq 0$. Let the function $f(x, z)$ of (1) satisfy the condition

$$
|f(x, z)| \leqq g(x,|z|) \text {. }
$$

Let $z(x)$ satisfy $|z(x)|>0$ and be a solution of (1) in the region $a \leqq x \leqq b$. Then for all $x$ in $a \leqq x \leqq b$, we have

$$
|z(x)| \leqq M(x)
$$

and

$$
|z(x)| \geqq m(x)
$$

where $M(x)$ and $m(x)$ are the maximal and minimal solutions of $u^{\prime}$ $= \pm g(x, u), u(a)=|z(a)|$, respectively.

Proof. The inequality (2) follows from the Theorem 1 in [4]. To prove (3), we have to use essentially the same argument as in [4] but now we have to consider the minimal solution of $u^{\prime}=-g(x, u)$, $u(a)=|z(a)|$ instead of the maximal solution of $u^{\prime}=g(x, u), u(a)$ $=|z(a)|$. This completes the proof.

REMARK. The above theorem includes the results of Bellman [1], Bihari [2] and Langenhop [3] as special cases. Taking $g(x, u)$ $=v(x) u$, it is easy to see that $M(x)=u(a) \exp \left[\int_{a}^{x} v(s) d s\right]$ and $m(x)$ $=u(a) \exp \left[-\int_{a}^{x} v(s) d s\right]$, which correspond to Bellman's results. Suppose $g(x, u)=v(x) g(u)$, where $g(u)>0$ for $u>0$. Then we can easily obtain $M(x)=G^{-1}\left[G(u(a))+\int_{a}^{x} v(s) d s\right]$ and

Received by the editors May 31, 1961.

${ }^{1}$ This work was supported by the Office of Naval Research. 


$$
m(x)=G^{-1}\left[G(u(a))-\int_{a}^{x} v(s) d s\right],
$$

where $G(u)=\int_{u_{0}}^{u}[g(r)]^{-1} d r, u_{0} \geqq 0$, which are exactly the results of Langenhop. This implies that the monotonicity assumption regarding $g(u)$ in his hypotheses is superfluous.

We can formulate an interesting comparison theorem. Consider another differential system

$$
z^{\prime}=h(x, z)
$$

under the assumptions:

(i) $x$ is a real variable, $z$ and $h$ are finite dimensional complex vectors with $n$ components $z_{i}$ and $h_{i}$ respectively,

(ii) $h$ is continuous in $(x, z)$ for all $z$ and for all $x$ in $a \leqq x \leqq b$.

THEOREM 2. Let the function $g(x, u) \geqq 0$ be continuous in a region $a \leqq x \leqq b, u \geqq 0$. Let the functions $f(x, z)$ and $h(x, z)$ satisfy the condition

$$
\left|f\left(x, z_{1}\right)-h\left(x, z_{2}\right)\right| \leqq g\left(x,\left|z_{1}-z_{2}\right|\right) .
$$

Let the functions $z_{1}(x)$ and $z_{2}(x)$ be solutions of (1) and (4) respectively and satisfy $\left|z_{1}(x)-z_{2}(x)\right|>0$. Then for all $x$ in $a \leqq x \leqq b$, we have

$$
\left|z_{1}(x)-z_{2}(x)\right| \leqq M(x) ; \quad\left|z_{1}(x)-z_{2}(x)\right| \geqq m(x),
$$

where $M(x)$ and $m(x)$ are the maximal and minimal solutions of $u^{\prime}= \pm g(x, u) ; u(a)=\left|z_{1}(a)-z_{2}(a)\right|$, respectively.

The proof is similar to that of the Theorem 1 and hence omitted. (Professor R. P. Boas informed me that essentially the same results by the same methods have been obtained independently by A. D. Zeibur.)

\section{REFERENCES}

1. R. Bellman, Stability theory of differential equations, McGraw-Hill, New York, 1953.

2. I. Bihari, $A$ generalisation of a lemma of Bellman and its application to uniqueness problems of differential equations, Acta Math. Acad. Sci. Hungar. 7 (1956), 81-94.

3. C. E. Langenhop, Bounds on the norm of a solution of a general differential equation, Proc. Amer. Math. Soc. 11 (1960), 795-799.

4. V. Lakshmikanth, On the boundedness of solutions of non-linear differential equations, Proc. Amer. Math. Soc. 8 (1957), 1044-1048.

University of Osmania, Hyderabad, India aNd University of California, Los ANGeles 